\title{
Prioritization of realignment associated with superior clinical outcomes for surgical cervical deformity patients
}

\begin{abstract}
Background: To optimize quality of life in patients with cervical deformity $(C D)$, there may be alignment targets to be prioritized.

Objective: To prioritize the cervical parameter targets for alignment.

Methods: Included: $\mathrm{CD}$ patients $\left(\mathrm{C} 2-\mathrm{C} 7 \mathrm{Cobb}>10^{\circ}\right.$, $\mathrm{C} 2-\mathrm{C} 7$ lordosis $[\mathrm{CL}]>10^{\circ}, \mathrm{CSVA}>4 \mathrm{~cm}$, or chin-brow vertical angle $>25^{\circ}$ ) with full baseline (BL) and 1-year (1Y) radiographic parameters and Neck Disability Index (NDI) scores; patients with cervical (C) or cervicothoracic (CT) Primary Driver Ames type. Patients with BL Ames classified as low $C D$ for both parameters of CSVA $(<4 \mathrm{~cm})$ and T1 slope minus CL (TS-CL) $\left(<15^{\circ}\right)$ were excluded. Patients assessed: Meeting Minimal Clinically Important Difference (MCID) for NDI (<-15 $\Delta \mathrm{NDI})$. Ratios of correction were found for regional parameters categorized by Primary Ames Driver (C or CT). Decision tree analysis assessed cut-offs for differences associated with meeting NDI MCID at 1 Y. Results: Seventy-seven CD patients (62.1 years, $64 \% \mathrm{~F}$, $\left.28.8 \mathrm{~kg} / \mathrm{m}^{2}\right) .41 .6 \%$ met MCID for NDI. A backward linear regression model including radiographic differences as predictors from $B L$ to $1 Y$ for meeting $\mathrm{MCID}$ for NDI demonstrated an $R^{2}=0.820(P=0.032)$ included TS-CL, CSVA, MGS, C2SS, C2-T3 angle, C2-T3 sagittal vertical axis (SVA), CL. By primary Ames driver, $67.5 \%$ of patients were $\mathrm{C}$, and $32.5 \% \mathrm{CT}$. Ratios of change in predictors for MCID NDI patients for $C$ and $C T$ were not significant between the two groups $(P>0.050)$. Decision tree analysis determined cut-offs for radiographic change, prioritizing in the following order: $\geq 42.5^{\circ}$ C2-T3 angle, $>35.4^{\circ} \mathrm{CL},<-31.76^{\circ} \mathrm{C} 2$ slope, $<-11.57 \mathrm{~mm}$ cSVA, $<-2.16^{\circ} \mathrm{MGS},>-30.8 \mathrm{~mm}$ C2-T3 SVA, and $\leq-33.6^{\circ} \mathrm{TS}-\mathrm{CL}$.

Conclusions: Certain ratios of correction of cervical parameters contribute to improving neck disability. Prioritizing these radiographic alignment parameters may help optimize patient-reported outcomes for patients undergoing $\mathrm{CD}$ surgery.
\end{abstract}

Keywords: Cervical deformity, prioritization, realignment

\begin{tabular}{|l|c|}
\hline \multicolumn{3}{|c|}{ Access this article online } \\
\hline \multirow{2}{*}{$\begin{array}{l}\text { Website: } \\
\text { www.jcvjs.com }\end{array}$} \\
\hline DOI: \\
10.4103/jcvjs.jcvjs_26_21
\end{tabular}

\author{
Katherine E. Pierce 1,2, Peter Gust Passias ${ }^{1,2}$, \\ Avery E. Brown ${ }^{1,2}$, Cole A. Bortz ${ }^{1,2}$, \\ Haddy Alas ${ }^{1,2}$, Renaud lafage ${ }^{3}$, Oscar Krol ${ }^{1,2}$, \\ Dean ChOu 4 , Douglas C. Burton 5 , Breton \\ Line ${ }^{6}$, Eric KLINeberg ${ }^{7}$, Robert Hart ${ }^{8}$, Jeffrey \\ Gum $^{9}$, Alan Daniels ${ }^{10}$, Kojo Hamilton ${ }^{11}$, \\ Shay Bess ${ }^{12}$, Themistocles Protopsaltis ${ }^{13}$, \\ Christopher Shaffrey ${ }^{14,15}$, Frank A. SchWab ${ }^{3}$, \\ Justin S. Smith ${ }^{16}$, Virginie Lafage ${ }^{3}$, Christopher \\ Ames $^{4}$, International Spine Study Group ${ }^{6}$
}

Departments of ${ }^{1}$ Orthopaedic and ${ }^{2}$ Neurologic Surgery, New York Spine Institute, NYU Langone Orthopedic Hospital, ${ }^{3}$ Department of Orthopedics, Hospital for Special Surgery, ${ }^{13}$ Department of Orthopaedics, NYU Langone Orthopedic Hospital, New York, NY, ${ }^{4}$ Department of Neurological Surgery, University of California, San Francisco, CA, ${ }^{5}$ Department of Orthopedic Surgery, University of Kansas Medical Center, Kansas City, KS, 'Department of Orthopaedic Surgery, University of California, Davis, CA, ${ }^{8}$ Department of Orthopaedic Surgery, Swedish Neuroscience Institute, Seattle, WA, ${ }^{9}$ Norton Leatherman Spine Center, Louisville, KY, ${ }^{10}$ Department of Orthopaedic Surgery, Warren Alpert School of Medicine, Brown University, Providence, RI, ${ }^{11}$ Department of Neurological Surgery, School of Medicine, University of Pittsburgh, Pittsburgh, PA, ${ }^{12}$ Department of Spine Surgery, Denver International Spine Clinic, Presbyterian St. Luke's/Rocky Mountain Hospital for Children, Denver, Colorado, Departments of ${ }^{14}$ Neurosurgery and ${ }^{15}$ Orthopaedic Surgery, Duke University Medical Center, Durham, NC, ${ }^{16}$ Department of Neurosurgery, University of Virginia, Charlottesville, VA, USA, ${ }^{6}$ Department of Spine Surgery, Denver International Spine Center, Presbyterian St. Luke's/Rocky Mountain Hospital for Children, Denver, CO

Address for correspondence: Dr. Peter Gust Passias, Division of Spinal Surgery/Departments of Orthopaedic and Neurosurgery, NYU Langone Medical Center, NYU School of Medicine, NY Spine Institute, Orthopaedic Hospital, 301, East $17^{\text {th }}$ St., New York, 10003, NY, USA. E-mail: peter.passias@nyumc.org

Submitted: 25-Feb-21

Accepted: 22-Jun-21

This is an open access journal, and articles are distributed under the terms of the Creative Commons Attribution-NonCommercial-ShareAlike 4.0 License, which allows others to remix, tweak, and build upon the work non-commercially, as long as appropriate credit is given and the new creations are licensed under the identical terms.

For reprints contact: WKHLRPMedknow_reprints@wolterskluwer.com

How to cite this article: Pierce KE, Passias PG, Brown AE, Bortz CA, Alas $\mathrm{H}$, Lafage $\mathrm{R}$, et al. Prioritization of realignment associated with superior clinical outcomes for surgical cervical deformity patients. J Craniovert Jun Spine 2021;12:311-7. 


\section{INTRODUCTION}

Incidence of adult cervical deformity (CD) as a distinct clinical diagnosis is rising, along with the literature concentrating on methodology for appropriately assessing the disease.$^{[1]}$ As the condition is often associated with major disability and neurologic compromise, surgical correction of malalignment and addressment of symptoms are often warranted..$^{[2,3]}$ Numerous studies have demonstrated radiographic alignment and achievement of sagittal balance as significant drivers of health-related-quality-of-life (HRQL) improvement in deformity patients, not specific to the cervical spine. ${ }^{[4-6]}$ Moreover, studies investigating the connection between cervical alignment parameters and HRQL outcomes is limited.

Restoration of cervical sagittal alignment involves neural element decompression and/or fusion of the cervical and caudal spinal regions, often invasive in nature and poses risks for major complications and poor patient-reported outcomes. ${ }^{[7]}$ Many patients are unable to undergo these major, invasive $\mathrm{CD}$ corrective procedures due to deformity severity, old age, comorbidities, and severe frailty status. Moreover, often baseline (BL) characteristics (body mass index [BMI], age, Charlson Comorbidity Index [CCI] score, frailty score) imply increased risk for certain postoperative complications and decline in HRQL outcomes. ${ }^{[8,9]}$ Alignment adjustments have been explored in the adult spinal deformity (ASD) population. Lafage et al proposed a modified version of the validated SRS-Schwab ASD classification accounting for varying age ranges. ${ }^{[10]}$ More rigorous alignment objectives were determined to be warranted for younger patients, while less rigorous alignment objectives for elderly patients, to achieve normative HRQL scores for each age population. ${ }^{[11]}$ This alignment specificity for the individual patient needs to be considered to optimize patient-reported outcomes.

Explicitly, when assessing deformity specific to the cervical spine, a standardized classification system of deformity severity is in its preliminary stages. The most well-known classification was created by Ames and the International Spine Study Group (ISSG), but it has yet to be formally validated with connection to HRQL outcomes. ${ }^{[12-14]}$ Little is known regarding the order of addressing correction of certain cervical alignment parameters for peak improvement in postoperative patient-reported outcomes. ${ }^{[15,16]}$ Using a prospective multicenter collection of CD surgical patients, this study investigated the prioritization of cervical alignment parameters and their minimal degree of correction that contributes to optimal quality of life.

\section{METHODS}

\section{Data source and inclusion criteria}

This was a retrospective cohort study of a prospective, multicenter ISSG database of CD patients enrolled from 2013 to 2018 at 13 participating centers around the United States. Institutional Review Board approval was required protocol by each site and informed patient consent was obtained. Patients enrolled in the database were greater than 18 years with evidence of one of the following $\mathrm{CD}$ BL radiographic parameters: cervical kyphosis ( $\mathrm{C} 2-\mathrm{C} 7 \mathrm{Cobb}$ angle $>10^{\circ}$ ), cervical scoliosis $\left(\mathrm{C} 2-\mathrm{C} 7\right.$ coronal $\mathrm{Cobb}$ angle $\left.<10^{\circ}\right), \mathrm{C} 2-\mathrm{C} 7$ sagittal vertical axis (cSVA) $>40 \mathrm{~mm}$ or chin-brow vertical angle (CBVA) $>25^{\circ}$. Database exclusion criteria comprised of patients with spinal deformity of neuromuscular etiology, presence of active infection, or malignancy. The study inclusion criteria required complete BL and 1-year (1Y) radiographic measurements and the health-related quality of life (HRQL) measure, Neck Disability Index (NDI), as well as demonstrated Cervical or Cervicothoracic Ames sagittal deformity driver descriptor. To analyze a more homogenous $\mathrm{CD}$ population, patients were excluded if they were categorized with another Ames driver (Thoracic [T], Coronal [S]) or were classified as a low Ames CD modifier for both the parameters of cSVA $(<4 \mathrm{~cm})$ and $\mathrm{T} 1$ slope minus C2-C7 lordosis (TS-CL) $\left(<15^{\circ}\right)$.

Data collection, radiographic, and health-related-quality-of-life assessment

Patient demographic and clinical data assessed patient age, gender, body mass index (BMI), and CCI. Operative factors assessed: surgical approach, levels fused, operative time, and estimated blood loss (EBL). Full-length free-standing lateral spine radiographs were used to assess the patient population at BL and 1Y. Radiographs were analyzed with SpineView ${ }^{\circledR}$ (ENSAM, Laboratory of Biomechanics, Paris, France) software according to the literature. ${ }^{[17-19 \mid}$ Radiographic parameters assessed included cervical sagittal vertical axis (cSVA), C2-C7 lordosis (CL), TS-CL, CBVA, McGregor's slope (MGS), C2-T3 sagittal vertical axis (SVA), C2-T3 angle, $\mathrm{C} 2$ slope. The health-related quality of life questionnaire utilized in this study was the NDI administered by each of the participating centers.

\section{Statistical analysis}

Descriptive analyses determined demographic, clinical, and surgical data. Frequency analysis evaluated categorical variables with Chi-square analysis determining the significant variance of expected versus observed values. Patients were assessed based on meeting the Minimal Clinically Important Difference (MCID) for NDI scores at $1 \mathrm{Y}(<-15 \Delta \mathrm{NDI})$. Proportion (\%) and difference of correction from preoperative 
Pierce, et al.: Prioritization of cervical deformity alignment

measurement to $1 \mathrm{Y}$ were calculated for the following regional parameters: cSVA, CL, T1 Slope, TS-CL, CBVA, MGS, C2-T3 SVA, C2-T3 Angle, and C2 Slope. Backward linear regression model including the radiographic differences (1Y - BL) as predictors for meeting MCID for NDI found the parameters that contributed the greatest variation (with a significantly large $R^{2}$ value). The radiographic measures included in the model were then assessed for the proportion of correction stratified by $\mathrm{C}$ or CT Ames primary driver type. Analysis of variance compared the $\mathrm{C}$ and $\mathrm{T}$ ratios for any significant differences. Random forest analysis generated 20,000 Conditional Inference Trees to determine cut-off values of the radiographic difference variables included in the backward regression model, accomplished through iteration of multivariate regression equations. Radiographic change cut-offs were prioritized based upon their ordinal regression values when entered as sole predictors for meeting MCID for NDI through binary logistic regressions. All statistical analyses were performed using SPSS software (version 21.0 IBM, Armonk, NY, USA) and R-statistical package (www.r-project. org). All analyses were two-sided and the level of significance was set to $<0.05$.

\section{RESULTS}

\section{Overall cohort patient characteristics}

Seventy-seven CD patients with complete radiographic and HRQL data met inclusion criteria for Ames driver descriptors of $\mathrm{C}$ or CT. 12 patients with $\mathrm{S}$ or T Ames driver descriptors were excluded. Mean patient age was 62.1 years, mean BMI of $28.8 \mathrm{~kg} / \mathrm{m}^{2}$, with $64 \%$ of the cohort as female. The average CCI score was 0.94 . By approach, these CD patients underwent majorly posterior surgeries (41.6\%), while $39 \%$ had combined approaches and $19.4 \%$ anterior. About $44.2 \%$ of patients underwent osteotomies and $53.2 \%$ decompression. The average levels fused was 7.5 (posterior: 8.3, anterior: 3.5). The mean total operative time was $553.1 \mathrm{~min}$, with an EBL of 1128.1 ccs. 32 patients (41.6\%) met MCID for NDI). $13 \%$ (10 patients) had a revision procedure. Table 1 summarizes the demographic and basic surgical factors for the cohort.

Baseline and 1-year radiographic parameters between $\mathrm{C}$ and $\mathrm{CT}$ ames drivers

Between $\mathrm{C}$ and CT groups, there were significant differences for both BL and $1 Y$ cohort means of cSVA, T1 Slope, C2-T3 SVA, and C2 Slope. CT patients exhibited significantly greater malalignment at BL for cSVA $(66.6 \mathrm{~mm}$ vs. $35.7 \mathrm{~mm}, P<0.001)$, T1 slope (41.4 ${ }^{\circ}$ vs. $\left.20.6^{\circ}, P<0.001\right)$, C2-T3 SVA $(110.2 \mathrm{~mm}$ vs. $57.2 \mathrm{~mm}, P<0.001)$, as well as $\operatorname{MGS}(P=0.042)$ and C2 slope $(P=0.008)$. C driver patients had greater $C L$ malalignment preoperatively $\left(-17.5^{\circ}\right.$ vs. $\left.-4.5^{\circ}\right)$. At $1 \mathrm{Y}$ CT
Table 1: Demographic and surgical characteristics of the cohort

\begin{tabular}{lc}
\hline Demographics & Mean \\
\hline Age (years) & 62.1 \\
Gender (female) (\%) & 64 \\
BMI (kg/m²) & 28.8 \\
Race (\%) & \\
White & 91.6 \\
Black & 5.6 \\
Other & 2.8 \\
CCl & 0.94 \\
Smoker (yes) (\%) & 6.5 \\
Surgical details (\%) & \\
Anterior only approach & 19.4 \\
Posterior only approach & 41.6 \\
Combined approach & 39 \\
Total levels fused & 7.5 \\
Osteotomy & 44.2 \\
Decompression & 53. \\
Operative time (min) & 553.1 \\
EBL (ccs) & 1128.1 \\
Revision & 13 \\
\hline BMI - Body mass index, EBL - Estimated blood loss, CCl Charlson comorbidity index
\end{tabular}

patients remained significantly more malaligned in cSVA, T1 slope, C2-T3 SVA, and C2 Slope (all $P<0.001$ ) [Table 2].

Radiographic corrective measures predictive of meeting minimal clinically important difference for Neck Disability Index

A backward linear regression model found the following radiographic differences as predictors of meeting MCID for NDI from BL to 1Y: TS-CL, cSVA, MGS, C2 Slope, C2-T3 angle, C2-T3 SVA and CL demonstrated the greatest variation contributing to MCID for NDI with an $R^{2}=0.820(P=0.032)$. When assessing individual Ames driver type cohorts, $C$ driver patients demonstrated an $R^{2}=0.844(P=0.029)$ without the inclusion of the TS-CL or C2-T3 SVA parameter. CT patients had an $R^{2}=0.778(P=0.025)$, without the TS-CL angle.

Ratios (\%) of correction in predictors by Ames driver Ratios of change in predictors for MCID NDI patients (BL-1Y) for C driver patients: $260.8 \%$ MGS, $140.3 \%$ CL, 121.2\% C2-T3 angle, $49.6 \%$ C2 slope, 41.1\% cSVA, 20.5\% TS-CL, 3.1\% C2-T3 SVA. Correction in CT driver patients included: $168.7 \% \mathrm{CL}$, 93\% MGS, 70.8\% C2-T3 angle, 31.1\% cSVA, 27.5\% C2 slope, 24.9\% TS-CL, $13.7 \%$ C2-T3 SVA. The ratios of radiographic differences were not significant between the $\mathrm{C}$ and CT driver groups $(P>0.050)$ [Table 2].

Prioritization of realignment parameters and their corrective cut-off values

Decision tree analysis determined cut-offs for radiographic change, prioritizing in the following order (based upon ordinal regression values): a correction $\geq 42.5^{\circ} \mathrm{C} 2-\mathrm{T} 3$ 
Table 2: Radiographic parameters at baseline and 1-year, as well as the difference between baseline and 1-year for cervical and cervicothoracic ames driver types

\begin{tabular}{lccc}
\hline & C & CT & $\boldsymbol{P}$ \\
\hline Baseline radiographic parameters & & & \\
CSVA (mm) & 35.7 & 66.6 & $<0.001$ \\
CL & $-17.5^{\circ}$ & $-4.5^{\circ}$ & 0.009 \\
T1 slope & $20.6^{\circ}$ & $41.4^{\circ}$ & $<0.001$ \\
TS-CL & $37.7^{\circ}$ & $45.5^{\circ}$ & 0.086 \\
CBVA & $0.41^{\circ}$ & $0.48^{\circ}$ & 0.893 \\
MGS & $2.9^{\circ}$ & $8.6^{\circ}$ & 0.042 \\
C2-T3 angle & $-18.6^{\circ}$ & $-27.0^{\circ}$ & 0.113 \\
C2-T3 SVA (mm) & 57.2 & 110.2 & $<0.001$ \\
C2 slope & $35.9^{\circ}$ & $49.2^{\circ}$ & 0.008 \\
At 1-year & & & \\
CSVA (mm) & 33.4 & 49.3 & $<0.001$ \\
CL & $4.4^{\circ}$ & $10.9^{\circ}$ & 0.064 \\
T1 slope & $28.3^{\circ}$ & $44.7^{\circ}$ & $<0.001$ \\
TS-CL & $23.9^{\circ}$ & $33.8^{\circ}$ & 0.001 \\
CBVA & $0.81^{\circ}$ & $3.3^{\circ}$ & 0.558 \\
MGS & $-2.2^{\circ}$ & $1.2^{\circ}$ & 0.150 \\
C2-T3 angle & $-0.29^{\circ}$ & $-2.3^{\circ}$ & 0.580 \\
C2-T3 SVA (mm) & 63.2 & 92.7 & $<0.001$ \\
C2 slope & $21.9^{\circ}$ & $33.3^{\circ}$ & $<0.001$ \\
Percentage of correction BL to 1 year (\%) & & & \\
CSVA & 41.1 & 31.1 & 0.904 \\
CL & 140.3 & 168.7 & 0.753 \\
TS-CL & 20.5 & 24.9 & 0.775 \\
MGS & 260.8 & 93 & 0.209 \\
C2-T3 angle & 121.2 & 70.8 & 0.193 \\
C2-T3 SVA & 3.1 & 13.7 & 0.052 \\
C2 slope & 49.6 & 27.5 & 0.830 \\
\hline
\end{tabular}

C - Cervical, CT - Cervicothoracic, SVA - Sagittal vertical axis, CSVA - Cervical SVA, CL - C2-C7 lordosis, TS-CL - T1 slope minus CL, CBVA - Chin-to-brow-vertical angle, MGS - McGregor's slope

angle (odds ratio [OR]: 5.667 [1.074-29.891], $P=0.041$ ), $>35.4^{\circ} \mathrm{CL}$ (OR: $\left.4.636[0.857-25.071], P=0.075\right),<-31.76^{\circ}$ C2 slope (OR: 3.2 [0.852-12.026], $P=0.085),<-11.57 \mathrm{~mm}$ CSVA (OR: 3.185 [1.137-8.917], $P=0.027),<-2.16^{\circ}$ MGS (OR: 2.724 [0.971-7.636], $P=0.057),>-30.8 \mathrm{~mm}$ C2-T3 SVA (OR: 0.462), and $\leq-33.6^{\circ}$ TS-CL (OR: 0.271) [Table 3].

Health-related-quality-of-lifes for patients with ideal prioritization

Patients who met thresholds for recommended cervical parameter prioritization trended toward improvement in both NDI and modified Japanese Orthopedic Association (mJOA) scale for all measurements at $1 \mathrm{Y}$ [Table 4].

\section{Case examples}

Figure 1 shows the BL and $1 \mathrm{Y}$ lateral cervical and whole spine radiographs of a 72 year-old female $\left(33.3 \mathrm{~kg} / \mathrm{m}^{2}\right)$ and a history of diabetes mellitus and osteopenia who underwent $\mathrm{CD}$ corrective surgery. She presented with cervical type Ames driver. According to proposed CD prioritization guidelines, this patient did not meet proposed prioritization correction thresholds for $\mathrm{C} 2-\mathrm{T} 3$ angle $\left(-1.60^{\circ}\right), \mathrm{CL}\left(+11.9^{\circ}\right)$, C2 slope $\left(-0.54^{\circ}\right), \mathrm{cSVA}(-2.03 \mathrm{~mm}), \operatorname{MGS}\left(+4.11^{\circ}\right)$, and TS-CL $\left(-0.69^{\circ}\right)$. She did meet the threshold for C2-T3 SVA $\left(+16.8^{\circ}\right)$. The patient had a $1 Y$ NDI score of 46 , did not meet MCID for NDI, and patient-reported mJOA score of 15 .

Figure 2 shows the BL and $1 Y$ lateral cervical and whole spine radiographs of a 61 -year-old male $\left(28.97 \mathrm{~kg} / \mathrm{m}^{2}\right)$ who underwent CD corrective surgery. He presented with cervical type Ames driver. According to proposed $\mathrm{CD}$ prioritization guidelines, this patient did meet all proposed prioritization correction thresholds for C2-T3 angle $\left(+76.1^{\circ}\right), \mathrm{CL}\left(+67.9^{\circ}\right)$, C2 slope $\left(-44.9^{\circ}\right)$, CSVA $(-11.9 \mathrm{~mm})$, MGS $\left(-10.8^{\circ}\right)$, C2-T3 SVA $\left(+11.7^{\circ}\right)$ and TS-CL $\left(-45.8^{\circ}\right)$. The patient had a 1Y NDI score of 11.1, met MCID for NDI, and patient-reported mJOA score of 18 .

\section{DISCUSSION}

High-risk cohorts undergoing treatment of adult CD include patients with advanced age, obesity, greater comorbidity burden, and severe frailty status. While classification systems, such as the one created by Ames and the ISSG, provide correction guidelines for the representative majority of $C D$ patients, operating on patients with the preoperative presentation of increased risk for poor outcomes has facilitated the need for prioritization of alignment scheme for $\mathrm{CD}$ surgery. ${ }^{[13]}$ Therefore, the goal for this analysis was to establish an order of targeting alignment parameters and their projected minimal corrective degree to benefit operative decision-making and inherently improve HRQL outcome management.

Utilizing a $\mathrm{CD}$ prospective multicenter database and bi-planar stereoradiography, allowing for the acquisition of full-body imaging in the weight-bearing position, our analysis determined that prioritizing regional cervical radiographic alignment parameters in a certain order to a specific degree optimized reaching the MCID in a patient's self-reported neck disability. Despite the regional driver of CD (cervical or cervicothoracic), radiographic correction for patients who reached MCID for NDI was similar. The prioritization of parameters is as follows: $\mathrm{C} 2-\mathrm{T} 3$ angle, $\mathrm{CL}, \mathrm{C} 2$ slope, cSVA, MGS, C2-T3 SVA, and finally, TS-CL.

First, we found that the C2-T3 angle should be corrected. This angle connects each of the regions of the spine, by incorporating the unequivocal relationship between the cervical and thoracolumbar spine morphology. ${ }^{[20-22]}$ By prioritizing next the $\mathrm{CL}$ correction, the natural cervical curvature is addressed secondarily. Cervical kyphosis is 
Pierce, et al.: Prioritization of cervical deformity alignment

Table 3: Order of prioritization based on binary logistic ordinal regression values of radiographic parameters and cut-off values for correction

\begin{tabular}{|c|c|c|c|c|c|}
\hline Radiographic parameters & OR & Lower Cl & Upper CI & $\boldsymbol{P}$ & Cut-offs of correction prioritized in order \\
\hline C2-T3 angle & 5.667 & 1.074 & 29.871 & 0.041 & C2-T3 angle $\Delta \geq 42.5^{\circ}$ \\
\hline $\mathrm{CL}$ & 4.636 & 0.857 & 25.071 & 0.075 & $\mathrm{CL} \Delta>35.4^{\circ}$ \\
\hline C2 slope & 3.200 & 0.852 & 12.026 & 0.085 & C2 slope $\Delta<-31.76^{\circ}$ \\
\hline cSVA & 3.185 & 1.137 & 8.917 & 0.027 & cSVA $\Delta<-11.57 \mathrm{~mm}$ \\
\hline MGS & 2.724 & 0.971 & 7.636 & 0.057 & $\operatorname{MGS} \Delta<-2.16^{\circ}$ \\
\hline C2-T3 SVA & 0.462 & 0.116 & 1.849 & 0.275 & C2-T3 SVA $\Delta>-30.8 \mathrm{~mm}$ \\
\hline TS-CL & 0.271 & 0.048 & 1.1516 & 0.137 & $\mathrm{TS}-\mathrm{CL} \Delta \leq-33.6^{\circ}$ \\
\hline
\end{tabular}

SVA - sagittal vertical axis, cSVA - Cervical SVA, CL - C2-C7 lordosis, TS - CL - T1 slope minus CL, MGS - McGregor's slope, OR - Odds ratio, Cl - Confidence interval

Table 4: Neck disability index and modified Japanese Orthopedic Association scale scores at 1-year between patients who met proposed prioritization cut-off values and those who did not

\begin{tabular}{|c|c|c|c|}
\hline & Met improvement threshold & Did not meet improvement threshold & $P$ \\
\hline \multicolumn{4}{|c|}{ NDI scores at 1-year } \\
\hline C2-T3 angle & 23.8 & 38 & $0.035^{*}$ \\
\hline $\mathrm{CL}$ & 24.7 & 37.6 & 0.071 \\
\hline C2 slope & 31.8 & 37 & 0.398 \\
\hline cSVA & 32.6 & 39.3 & 0.158 \\
\hline MGS & 32.9 & 42.4 & 0.055 \\
\hline C2-T3 SVA & 34.7 & 45.5 & 0.130 \\
\hline $\mathrm{TS}-\mathrm{CL}$ & 28.2 & 37 & 0.253 \\
\hline \multicolumn{4}{|c|}{ mJOA scores at 1-year } \\
\hline C2-T3 angle & 15.78 & 14 & 0.087 \\
\hline $\mathrm{CL}$ & 15 & 14.15 & 0.442 \\
\hline C2 slope & 14.58 & 14.19 & 0.673 \\
\hline cSVA & 14.8 & 13.73 & 0.152 \\
\hline MGS & 14.58 & 13.61 & 0.197 \\
\hline C2-T3 SVA & 14.38 & 13.5 & 0.422 \\
\hline $\mathrm{TS}-\mathrm{CL}$ & 15 & 14.17 & 0.477 \\
\hline
\end{tabular}

NDI - Neck disability index, SVA - Sagittal vertical axis, cSVA - Cervical SVA, CL - C2-C7 lordosis, TS - CL - T1 slope minus CL, MGS - McGregor's slope, mJ0A - Modified Japanese Orthopedic Association scale

a major radiographic presentation of $\mathrm{CD}$, with a strong connection to clinical impact, so direct correction to parameters encompassing the curve is imperative for improved patient-reported outcomes. ${ }^{[20]}$ In a previous study by Passias et al., the preoperative cervical degree of lordotic compensation and higher C2-T3 angle were identified as risk factors for sagittal malalignment and decline in HRQL outcomes after thoracolumbar surgery. ${ }^{[23]}$ With prioritization of the lordosis of the spine, combined with the cervicothoracic junction as a site of transition between the highly mobile cervical and rigid thoracic systems, we can address the inherent relationship between cervical sagittal malalignment and clinical measures of disability. ${ }^{[24]}$

The third parameter to prioritize in the correction of $\mathrm{CD}$ is the C2 slope. We found that correction of this radiographic measurement led to increased neck disability improvement. ${ }^{[25]}$ This parameter is a singular CD factor, a mathematical approximation of the mismatch between T1 slope and cervical lordosis. ${ }^{[26]}$ By factoring in the occipitocervical spine, the $\mathrm{C} 2$ slope accounts for an additional aspect of radiographic alignment improvement and should be prioritized accordingly.

Then, the cSVA was found to be prioritized. The restoration of this parameter has been correlated with improved postoperative outcomes and the prevention of disability. ${ }^{[27]}$ It incorporates a global assessment of $\mathrm{CD}$ by measuring the distance between the C2 and C7 plumblines. ${ }^{\mid 28]}$ Tang et al. suggested that an increasing cervical SVA is a cause for clinical concern of cervical malalignment, as $>40 \mathrm{~mm}$ was correlated with worse NDI outcomes. ${ }^{[29]}$ As one of the main objectives of CD surgery is the maintenance or restoration of horizontal gaze, the next parameter to prioritize was found to be MGS. ${ }^{[30]}$ By correcting this angle, the symptoms of inability to look straight ahead or lie down flat that contribute to overall disability can be addressed. Another parameter appreciating cervical sagittal alignment is the C2-T3 SVA, which was found to be the $6^{\text {th }}$ measure of prioritization. Prioritizing the two large measures of cervical sagittal alignment (C2-C7 SVA and C2-T3 SVA), accounting for the alignment of subjacent segments, including the thoracolumbar spine and pelvis, 


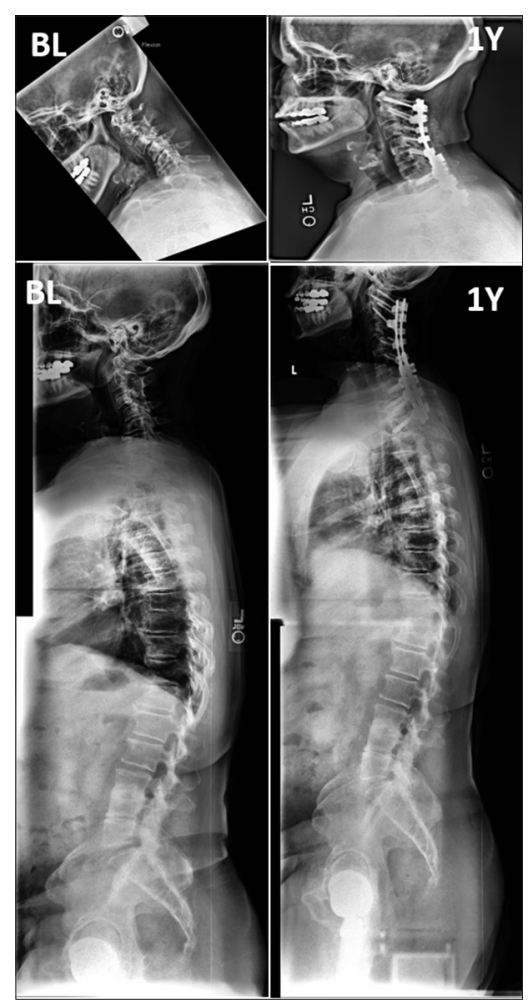

Figure 1: Baseline and 1-year cervical and whole spine radiographs of a 72-year-old female who did not meet proposed radiographic prioritization of alignment

along with horizontal gaze measurement, the global outlook of the spine is assessed.

Finally, the mismatch between T1 slope and CL parameter was prioritized. This relationship accounts for the intrinsic compensation of $\mathrm{T} 1$ slope on the $\mathrm{CL}$ to balance the head over the thoracic inlet and maintain the physiological neck tilting. ${ }^{[31,32]}$ The measure accounts for the patient's center of gravity and contributes to overall cervical integration into global alignment.

Through the combination of regional cervical radiographic factors, we found that prioritizing the lordosis of the cervical spine (through $\mathrm{C} 2-\mathrm{C} 7$ and $\mathrm{C} 2-\mathrm{T} 2$ ), followed by occipitocervical incorporation (C2 slope) global assessment (cSVA, C2-T3 SVA, TS-CL), and horizontal improvement (MGS). This proposed prioritization involves the innate interdependence of the spine: cervical lordosis depends on both thoracic kyphosis and lumbar lordosis. With the distinct diagnosis of $\mathrm{CD}$, cervical lordosis adaptation is due to the cervical spinal segment changes relative to the global spine to attempt to maintain the head over the pelvis and horizontal gaze ${ }^{|28|}$ Addressing the intertwined cervical parameters in a specific order to a certain degree of correction can contribute to improved patient-reported neck disability.

Our study is not without limitations, including the retrospective nature of this study and the small number

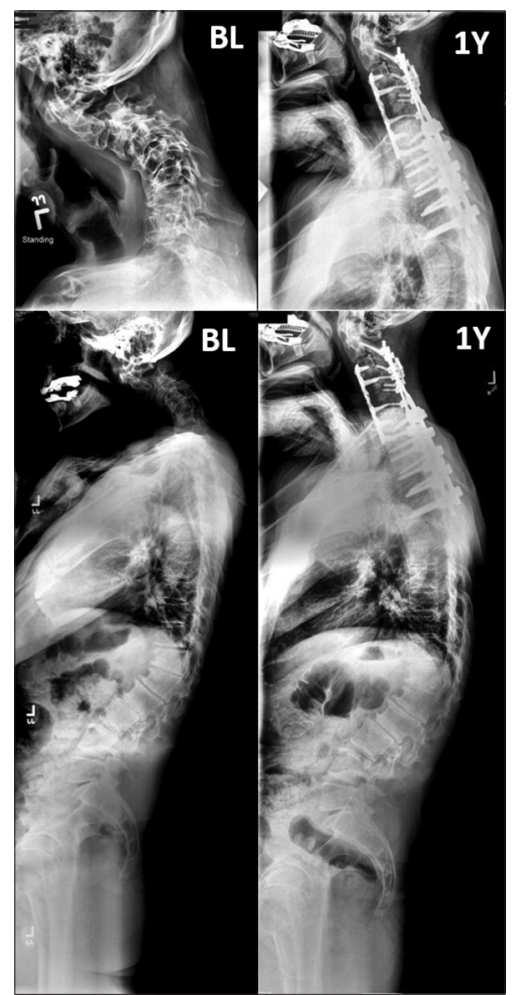

Figure 2: Baseline and 1-year cervical and whole spine radiographs for a 61-year-old male who met proposed radiographic prioritization of alignment

of patients. While the multicenter methodology used for database construction increases the generalizability of our findings, the data analyzed for the purposes of this study may be skewed toward more complex cases. Another limitation lies in the heterogeneous nature of the patient population in regards to cervical procedure and complexity, which may have been accounted for by removing thoracic and coronal Ames type $C D$ drivers. Future studies should investigate the proposed prioritization and thresholds on a prospective trial with a larger, homogenous population of patients undergoing CD corrective surgery.

\section{CONCLUSIONS}

Certain ratios of correction of cervical parameters contribute to improving neck disability. Specific cut-offs of radiographic differences from BL to $1 \mathrm{Y}$ were found prioritizing $\mathrm{C} 2-\mathrm{T} 3$ angle, followed by cervical lordosis, $\mathrm{C} 2$ slope, $\mathrm{C} 2-\mathrm{C} 7$ plumb line, MGS, C2-T3 SVA, and TS-CL all strongly associated with meeting the MCID for the NDI score. Prioritizing these radiographic alignment parameters may help optimize patient-reported outcomes for patients undergoing $C D$ surgery.

\section{Financial support and sponsorship}

The International Spine Study Group (ISSG) is funded through research grants from DePuy Synthes and individual donations. 
Pierce, et al.: Prioritization of cervical deformity alignment

\section{Conflicts of interest}

There are no conflicts of interest.

\section{REFERENCES}

1. Smith JS, Line B, Bess S, Shaffrey CI, Kim HJ, Mundis G, et al. The health impact of adult cervical deformity in patients presenting for surgical treatment: Comparison to united states population norms and chronic disease states based on the EuroQuol-5 dimensions questionnaire. Neurosurgery 2017;80:716-25. doi: 10.1093/neuros/ nyx028.

2. Chi JH, Tay B, Stahl D, Lee R. Complex deformities of the cervical spine. Neurosurg Clin N Am 2007;18:295-304.

3. Grob D, Frauenfelder H, Mannion AF. The association between cervical spine curvature and neck pain. Eur Spine J 2007;16:669-78.

4. Ames CP, Smith JS, Scheer JK, Bess S, Bederman SS, Deviren V, et al. Impact of spinopelvic alignment on decision making in deformity surgery in adults: A review. J Neurosurg Spine 2012;16:547-64.

5. Hallager DW, Hansen LV, Dragsted CR, Peytz N, Gehrchen M, Dahl B. A comprehensive analysis of the SRS-Schwab Adult Spinal Deformity Classificaxtion and confounding variables - A prospective, non-US cross-sectional study in 292 patients. Spine (Phila Pa 1976) 2016;41:E589-97.

6. Schwab F, Ungar B, Blondel B, Buchowski J, Coe J, Deinlein D, et al. Scoliosis Research Society-Schwab adult spinal deformity classification: a validation study. Spine (Phila Pa 1976) 2012;37:1077-82.

7. Ailon T, Smith JS, Shaffrey CI, Kim HJ, Mundis G, Gupta M, et al. Outcomes of operative treatment for adult cervical deformity: A prospective multicenter assessment with 1-year follow-up. Neurosurgery 2018;83:1031-9.

8. Miller EK, Ailon T, Neuman BJ, Klineberg EO, Mundis GM Jr, Sciubba DM, et al. Assessment of a novel adult cervical deformity frailty index as a component of preoperative risk stratification. World Neurosurg 2018;109:e800-6.

9. Passias PG, Poorman GW, Horn SR, Jalai CM, Bortz C, Segreto F, et al. Effect of obesity on radiographic alignment and short-term complications after surgical treatment of adult cervical deformity. World Neurosurg 2019; 125:e1082-8.

10. Lafage R, Schwab F, Glassman S, Bess S, Harris B, Sheer J, et al. Age-adjusted alignment goals have the potential to reduce PJK. Spine (Phila Pa 1976) 2017;42:1275-82.

11. Lafage R, Schwab F, Glassman S, Bess S, Harris B, Sheer J, et al. Ageadjusted alignment goals have the potential to reduce PJK. Spine (Phila Pa 1976) 2017;42:1275-82.

12. Protopsaltis TS, Ramchandran S, Hamilton DK, Sciubba D, Passias PG, Lafage $\mathrm{V}$, et al. Analysis of successful versus failed radiographic outcomes after cervical deformity surgery. Spine (Phila Pa 1976) 2018;43:E773-81.

13. Ames CP, Smith JS, Eastlack R, Blaskiewicz DJ, Shaffrey CI, Schwab F, et al. Reliability assessment of a novel cervical spine deformity classification system. J Neurosurg Spine 2015;23:673-83.

14. Bakouny Z, Khalil N, Otayek J, Bizdikian AJ, Yared F, Salameh M, et al. Are the sagittal cervical radiographic modifiers of the Ames-ISSG classification specific to adult cervical deformity? J Neurosurg Spine 2018;29:483-90.

15. Passias PG, Jalai CM, Smith JS, Lafage V, Diebo BG, Protopsaltis T, et al. Characterizing adult cervical deformity and disability based on existing cervical and adult deformity classification schemes at presentation and following correction. Neurosurgery 2017;82:192-201.

16. Passias PG, Horn SR, Oh C, Ramchandran S, Burton DC, Lafage V, et al. Evaluating cervical deformity corrective surgery outcomes at 1-year using current patient-derived and functional measures: Are they adequate? J Spine Surg 2018;4:295-303.

17. Champain S, Benchikh K, Nogier A, Mazel C, Guise JD, Skalli W. Validation of new clinical quantitative analysis software applicable in spine orthopaedic studies. Eur Spine J 2006;15:982-91.

18. O'Brien MF, Kuklo TRTR, Blanke KM, et al. Spinal Deformity Study Group Radiographic Measurement Manual. Available from: http://www.oref.org/docs/default-source/default-document-library/ sdsg-radiographic-measuremnt-manual.pdf?sfvrsn=2. 2005. [Last accessed on $2020 \mathrm{Jul} 10]$.

19. Rillardon L, Levassor N, Guigui P, Wodecki P, Cardinne L, Templier A, et al. Validation of a tool to measure pelvic and spinal parameters of sagittal balance. Rev Chir Orthop Reparatrice Appar Mot 2003;89:218-27.

20. Passias PG, Oh C, Jalai CM, Worley N, Lafage R, Scheer JK, et al. Predictive model for cervical alignment and malalignment following surgical correction of adult spinal deformity. Spine (Phila Pa 1976) 2016;41:E1096-103.

21. Wang VY, Chou D. The cervicothoracic junction. Neurosurg Clin N Am 2007; 18:365-71.

22. Diebo BG, Ferrero E, Lafage R, Challier V, Liabaud B, Liu S, et al. Recruitment of compensatory mechanisms in sagittal spinal malalignment is age and regional deformity dependent: A full-standing axis analysis of key radiographical parameters. Spine (Phila Pa 1976) 2015;40:642-9.

23. Passias PG, Soroceanu A, Scheer J, Yang S, Boniello A, Smith JS, et al. Magnitude of preoperative cervical lordotic compensation and C2-T3 angle are correlated to increased risk of postoperative sagittal spinal pelvic malalignment in adult thoracolumbar deformity patients at 2-year follow-up. Spine J 2015;15:1756-63.

24. Protopsaltis TS, Scheer JK, Terran JS, Smith JS, Hamilton DK, Kim HJ, et al. How the neck affects the back: Changes in regional cervical sagittal alignment correlate to HRQOL improvement in adult thoracolumbar deformity patients at 2-year follow-up. J Neurosurg Spine 2015;23:153-8.

25. Protopsaltis TS, Lafage R, Vira S, Sciubba D, Soroceanu A, Hamilton K, et al. Novel angular measures of cervical deformity account for upper cervical compensation and sagittal alignment. Clin Spine Surg 2017;30:E959-67.

26. Protopsaltis T, Schwab F, Bronsard N, Smith JS, Klineberg E, Mundis G, et al. TheT1 pelvic angle, a novel radiographic measure of global sagittal deformity, accounts for both spinal inclination and pelvic tilt and correlates with health-related quality of life. J Bone Joint Surg Am 2014;96:1631-40.

27. Goldschmidt E, Angriman F, Agarwal N, Trevisan M, Zhou J, Chen K, et al. A new piece of the puzzle to understand cervical sagittal alignment: Utilizing a novel angle delta to describe the relationship among T1 vertebral body slope, cervical lordosis, and cervical sagittal alignment. Neurosurgery 2020;86:446-51.

28. Scheer JK, Tang JA, Smith JS, Acosta FL Jr., Protopsaltis TS, Blondel B, et al. Cervical spine alignment, sagittal deformity, and clinical implications: A review. J Neurosurg Spine 2013;19:141-59.

29. Tang JA, Scheer JK, Smith JS, Deviren V, Bess S, Hart RA, et al. The impact of standing regional cervical sagittal alignment on outcomes in posterior cervical fusion surgery. Neurosurgery 2015;76 Suppl 1:S14-21.

30. Suk KS, Kim KT, Lee SH, Kim JM. Significance of chin-brow vertical angle in correction of kyphotic deformity of ankylosing spondylitis patients. Spine (Phila Pa 1976) 2003;28:2001-5.

31. Jeon SI, Hyun SJ, Han S, Lee BH, Kim KJ, Jahng TA, et al. Relationship between cervical sagittal alignment and patient outcomes after anterior cervical fusion surgery involving 3 or more levels. World Neurosurg 2018;113:e548-54.

32. Lee SH, Kim KT, Seo EM, Suk KS, Kwack YH, Son ES. The influence of thoracic inlet alignment on the craniocervical sagittal balance in asymptomatic adults. J Spinal Disord Tech 2012;25:E41-7. 